\title{
BCG vaccination-induced long-lasting control of Mycobacterium tuberculosis correlates with the accumulation of a novel population of CD4 ${ }^{+} \mathrm{IL}-17^{+} \mathrm{TNF}^{+} \mathrm{IL}^{2} 2^{+}$T cells
}

\author{
Andrea Cruz $^{\mathrm{a}, \mathrm{b}}$, Egídio Torrado ${ }^{\mathrm{a}, \mathrm{b}}$, Jenny Carmona ${ }^{\mathrm{a}, \mathrm{b}}$, Alexandra G. Fraga ${ }^{\mathrm{a}, \mathrm{b}}$, \\ Patrício Costa ${ }^{a, b}$, Fernando Rodrigues ${ }^{a, b}$, Rui Appelberg ${ }^{c}$, Margarida Correia-Neves ${ }^{a, b}$, \\ Andrea M. Cooper ${ }^{\mathrm{d}}$, Margarida Saraiva ${ }^{\mathrm{a}, \mathrm{b}}$, Jorge Pedrosa ${ }^{\mathrm{a}, \mathrm{b}}$, António G. Castro ${ }^{\mathrm{a}, \mathrm{b}, *}$ \\ ${ }^{a}$ Life and Health Sciences Research Institute (ICVS), School of Health Sciences, University of Minho, Braga, Portugal \\ b ICVS/3B's-PT Government Associate Laboratory, Braga/Guimarães, Portugal \\ 'Institute for Molecular and Cell Biology (IBMC), University of Porto, Porto, Portugal \\ d Trudeau Institute, Saranac Lake, NY 12983, United States
}

\section{A R T I C L E I N F O}

\section{Article history:}

Received 25 July 2014

Received in revised form 7 November 2014

Accepted 10 November 2014

Available online 20 November 2014

\section{Keywords:}

Tuberculosis

BCG vaccination

Multifunctional $\mathrm{CD} 4^{+} \mathrm{T}$ cells

Effector $\mathrm{CD} 4^{+} \mathrm{T}$ cells

Memory $\mathrm{CD}^{+} \mathrm{T}$ cells

\begin{abstract}
A B S T R A C T
Mycobacterium bovis Bacille Calmette-Guerin (BCG) is the only vaccine in use to prevent Mycobacterium tuberculosis (Mtb) infection. Here we analyzed the protective efficacy of BCG against Mtb challenges 21 or 120 days after vaccination. Only after 120 days post-vaccination were mice able to efficiently induce early Mtb growth arrest and maintain long-lasting control of Mtb. This protection correlated with the accumulation of $\mathrm{CD}^{+} \mathrm{T}$ cells expressing IL-17 ${ }^{+} \mathrm{TNF}^{+} \mathrm{IL}-2^{+}$. In contrast, mice challenged with Mtb 21 days after BCG vaccination exhibited only a mild and transient protection, associated with the accumulation of $\mathrm{CD} 4^{+} \mathrm{T}$ cells that were mostly IFN- $\gamma^{+} \mathrm{TNF}^{+}$and to a lesser extent IFN- $\gamma^{+} \mathrm{TNF}^{+} \mathrm{IL}-2^{+}$. These data suggest that the memory response generated by BCG vaccination is functionally distinct depending upon the temporal proximity to BCG vaccination. Understanding how these responses are generated and maintained is critical for the development of novel vaccination strategies against tuberculosis.
\end{abstract}

(c) 2014 Elsevier Ltd. All rights reserved.

\section{Introduction}

Tuberculosis (TB) remains a major public health problem. With approximately one-third of the world's population latently infected with Mycobacterium tuberculosis (Mtb), a staggering 8.7 million new cases and 1.4 million deaths are reported annually [1]. Mycobacterium bovis Bacille Calmette-Guerin (BCG) is the only vaccine currently available, but its efficacy against pulmonary TB is variable [2,3]. Nevertheless, BCG is still in use in multiple countries due to its efficacy in protecting against disseminated forms of TB in children [2]. For this reason, heterologous prime-boost regimens involving priming with BCG followed by an adjuvanted or vectored subunit boost are proposed as promising vaccine strategies against TB [4-6]. However, in a recent clinical trial, this approach proved insufficient in preventing Mtb infection or TB disease [7].

\footnotetext{
* Corresponding author at: Life and Health Sciences Research Institute (ICVS), School of Health Sciences, University of Minho, Campus de Gualtar 4710-057 Braga, Portugal. Tel.: +351 253604815; fax: +351 253604809.

E-mail address: acastro@ecsaude.uminho.pt (A.G. Castro).
}

For a vaccine to induce protection against TB, antigen-specific $\mathrm{T}$ cells should be recruited rapidly to the lungs and activate the infected phagocytes to control Mtb [8,9]. In addition, the cells reaching the infection site should be able to survive within the phagocyte laden environment $[10,11]$. While $C D 4^{+}$IFN- $\gamma^{+}$T cells are thought to be essential for Mtb control [12,13], the magnitude of the IFN- $\gamma$ response does not provide a good correlate of protection against TB [14-16]. Moreover, recent data suggest that $\mathrm{CD} 4^{+} \mathrm{T}$ cells producing multiple cytokines, including IFN- $\gamma$, TNF, and IL- 2 are associated with protection against Mtb infection [17-20] suggesting that, specific populations of $\mathrm{CD}^{+} \mathrm{T}$ cells that produce multiple cytokines play important roles in the control of TB.

In recent years, $\mathrm{CD}^{+} \mathrm{T}$ cells capable of producing IL-17 have been associated with protection against infection by several pathogens [21]. During TB, $C D 4^{+} I L-17^{+} \mathrm{T}$ cells are particularly important in vaccine-mediated immunity $[9,22]$ by promoting a more rapid recruitment of $\mathrm{CD} 4^{+} \mathrm{IFN}-\gamma^{+} \mathrm{T}$ cells to the lungs of Mtb infected mice, leading to an earlier control of Mtb proliferation [9]. The importance of multifunctional T cell populations [17-20] together with the differential efficacy of effector versus memory responses in the control of Mtb [23,24], led us to determine the 
phenotype and function of both the effector and memory responses induced by BCG vaccination in the control of Mtb infection. To this end, we challenged mice with Mtb 21 (effector) or 120 (memory) days after BCG vaccination to determine the protective efficacy of each regimen and to correlate protection with the phenotype of the $\mathrm{CD} 4^{+} \mathrm{T}$ cell response.

We show that, while both the effector and memory responses generated by BCG vaccination are equally effective at inducing early Mtb growth arrest, this does not correlate with the magnitude of the IFN- $\gamma$ response. Indeed, both mice challenged with Mtb 21 and 120 days after BCG vaccination were equally able to induce Mtb growth arrest, however long-lasting protection was a feature of the 120 day but not the 21 day regimen. This long-lived protection is associated with the accumulation of multifunctional CD $4^{+} \mathrm{IL}-17^{+} \mathrm{T}$ cells, including $\mathrm{CD}^{+} \mathrm{IL}^{-} 17^{+} \mathrm{TNF}^{+} \mathrm{IL}_{-} 2^{+}$. These data highlight the complexity of $\mathrm{CD}^{+} \mathrm{T}$ cell phenotypes that are generated by BCG vaccination and the importance of specific subsets in vaccine-mediated immunity. Understanding the mechanisms underlying the generation of these subsets will be critical in the development of novel vaccine strategies against TB.

\section{Materials and methods}

\subsection{Mice}

Eight to 12-week-old female C57BL/6 mice were obtained from Charles River (Barcelona, Spain) and maintained at the ICVS animal facility. All animal experiments were performed according to the European Union Directive 86/609/EEC and were approved by the Portuguese national authority, Direção Geral de Veterinária.

\subsection{Bacteria}

Mtb H37Rv and M. bovis BCG Pasteur were originally obtained from the Trudeau Institute Mycobacterial Collection. Bacteria were grown in Proskauer Beck medium containing 0.05\% Tween 80 to mid-log phase and frozen at $-70^{\circ} \mathrm{C}$ until use.

\subsection{Vaccination, experimental infection and bacterial load determination}

Mice were vaccinated with $1 \times 10^{6}$ BCG via the subcutaneous route. At 21 or 120 days after vaccination, mice were anesthetized with Ketamine/Medetomidine and infected via the intranasal route with $4 \times 10^{4} \mathrm{CFU}$ of Mtb, resulting in a lung dose of $2.47 \pm 0.23$ $\log _{10}$ [25]. For bacterial load determination, mice were killed by $\mathrm{CO}_{2}$ asphyxiation, the lungs were aseptically excised, individually homogenized, followed by plating serial dilution of the homogenate on nutrient 7H11 agar (BD Biosciences). CFUs were counted after 3 weeks of incubation at $37^{\circ} \mathrm{C}$. This procedure was followed to control for the presence of viable BCG in the lung at the time of Mtb challenge and no viable BCG bacteria were found in any of the experiments performed.

\subsection{Quantification of antigen-specific responses by ELISPOT, and intracellular cytokine staining}

Lungs and draining lymph nodes (LN) were aseptically removed and single cell suspensions prepared [25]. The quantification of Ag85B $280-294$ and ESAT- $6_{1-20}$-specific CD $4^{+}$T cells was determined by ELISpot, as these peptides represent previously described I- $A^{\text {b }}$ restricted antigens to which there is an early focus of the $T$ cell response $[25,26]$. Briefly, $1 \times 10^{5}$ cells were incubated in antibodycoated plates with irradiated splenocytes, $10 \mathrm{ng} / \mathrm{ml}$ of IL-2 and $1 \mu \mathrm{g} / \mathrm{ml}$ of cognate peptide. After $24 \mathrm{~h}$ of incubation, plates were processed for the detection of IFN- $\gamma$ or IL-17 producing cells. Cells cultured in the absence of antigen and cells from uninfected and unvaccinated mice were used as controls.

For intracellular cytokine staining, lung and LN cells were stimulated with $50 \mathrm{ng} / \mathrm{ml}$ of PMA plus $500 \mathrm{ng} / \mathrm{ml}$ of Ionomycin in the presence of $10 \mu \mathrm{g} / \mathrm{ml}$ of Brefeldin A for $4 \mathrm{~h}$ at $37^{\circ} \mathrm{C}$. Cells were then fixed overnight at $4{ }^{\circ} \mathrm{C}$ before they were washed, permeabilized, using the Cytofix/Cytoperm Kit (BD Pharmingen), and stained for surface and intracellular antigens for $20 \mathrm{~min}$ at $4{ }^{\circ} \mathrm{C}$. Antibodies for CD3 (145-2C11), CD4 (GK1.5), CCR6 (29-2L17), CCR7 (4B12), CD62L (Mel-14), CD11b (M1/70), Gr-1 (RB6-8C5), IFN- $\gamma$ (XMG1.2), IL-17 (TC11-18H10.1), IL-2 (JES6-5H4) and TNF (MP6-XT22) were obtained from BD biosciences, eBioscience or Biolegend. Samples were acquired on a LSRII flow cytometer (BD Biosciences) and the data were analyzed using FlowJo software (TreeStar). The gating strategy can be found in Fig. S2A.

\section{5. $R T-P C R$}

Total lung RNA was extracted using TRIzol ${ }^{\circledR}$ Reagent (Invitrogen) and reverse transcribed using the SuperScript II (Invitrogen) and Oligo(dT) (Roche), according to the manufacturer's instructions. Target gene mRNA expression was quantified using SYBR green (Qiagen) and specific oligonucleotides [27]. A typical real-time RT-PCR protocol was performed under the following conditions: $15 \mathrm{~min}$ at $95^{\circ} \mathrm{C}$, followed by 40 cycles $\left(95^{\circ} \mathrm{C}\right.$ denaturing for $15 \mathrm{~s} ; 58^{\circ} \mathrm{C}$ annealing for $20 \mathrm{~s} ; 72^{\circ} \mathrm{C}$ extension for $15 \mathrm{~s}$ ), melting at $60^{\circ} \mathrm{C}$ until $95^{\circ} \mathrm{C}$ for $5 \mathrm{~s}$, and finally cooling. The specificity of the SYBR green assays was confirmed by melting point analysis. Data were normalized to ubiquitin mRNA levels, using the following equation: $1.8^{\text {(ct reference gene }-\mathrm{ct} \text { target gene) }} \times 100,000$.

\subsection{Histological and morphometric analysis}

The caudal lobe of each lung was inflated with neutral buffered formalin and processed for hematoxylin and eosin stain. Sections were screened and scored in a blinded manner by a qualified pathologist [25].

Immunofluorescence was performed on formalin-fixed tissue sections as previously described [28]. Briefly, antigens were unmasked and blocked with donkey serum and FcBlock, and endogenous biotin was neutralized. Sections were probed with purified goat anti-iNOS (M-19) followed by a secondary donkey anti-goat antibody (Invitrogen). SlowFade Gold antifade with DAPI (Invitrogen) was used to detect nuclei. Images were obtained with an Olympus BX61 microscope and were recorded with a digital camera (DP70).

\subsection{Statistical analysis}

Data points represent means \pm SEM. Two-way ANOVA with Bonferroni's posttest was used to compare groups using Graphpad Prism Software. Means were considered significant for $p \leq 0.05$.

\section{Results}

\subsection{The efficacy of BCG-mediated control of Mtb is dependent on the length of time between vaccination and Mtb challenge}

To address the efficiency of the effector versus the memory response generated by BCG vaccination, we challenged mice with Mtb 21 (effector) or 120 (memory) days after vaccination and determined their ability to induce early growth arrest and maintain long-lasting control of Mtb. Mice challenged 120 days after BCG vaccination manifested improved and early control of Mtb, when compared to mice challenged 21 days after BCG vaccination (Fig. 1A). Moreover, the latter group showed a transient protection 
A

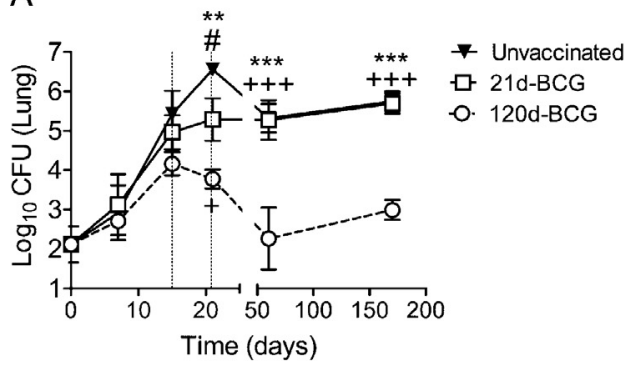

B

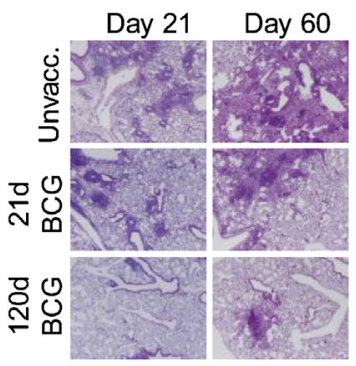

D

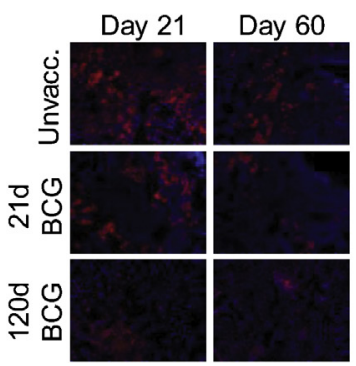

C

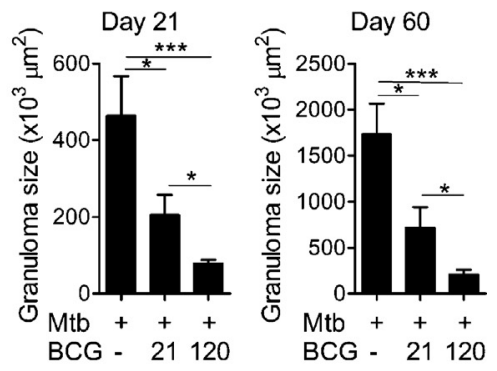

E

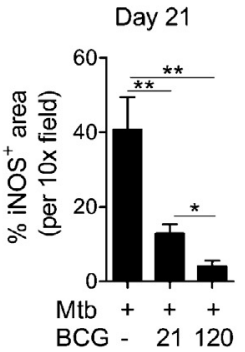

the presence of particular antigen-specific $\mathrm{T}$ cell populations at the time of challenge.

To answer this, we first determined the frequencies of effector memory $\left(\mathrm{T}_{\mathrm{EM}}\right)$ and central memory $\left(\mathrm{T}_{\mathrm{CM}}\right) \mathrm{CD}^{+} \mathrm{T}$ cells within the lungs of the vaccinated and unvaccinated mice just prior to challenge [29]. We found a predominance of $\mathrm{T}_{\mathrm{EM}}$ cells in the lungs of mice that were vaccinated 21 days before Mtb challenge, whereas $\mathrm{T}_{\mathrm{CM}}$ cells were more prevalent in mice vaccinated for 120 days (Fig. 2A). Next, we characterized the Ag-specific T cell response, by comparing the number and frequency of cytokine producing Ag85specific T cells. Mice that were vaccinated for 21 days before the Mtb challenge had a higher number (Fig. 2B) and frequency (Fig. S1A) of IFN- $\gamma$-producing Ag85-specific T cells than mice vaccinated 120 days before the Mtb challenge. In contrast, there was an increased number (Fig. 2D) and frequency (Fig. S1B) of IL-17-producing T cells in the mice vaccinated 120 days prior to challenge. That this ex vivo response mimicked the in vivo situation is illustrated by the decreased expression of IFN- $\gamma$ (Fig. 2C) and increased expression of IL-17 mRNA (Fig. 2E) in the whole lung tissue of the mice vaccinated 120 days before challenge. We also characterized the $\mathrm{CD} 4^{+} \mathrm{T}$ cells within the lungs of mice prior to challenge and found that there was a significantly higher frequency of $\mathrm{CD} 4^{+} \mathrm{T}$ cells expressing CCR6, a chemokine receptor important for the migration of Th17 cells [30] in the lungs of the mice vaccinated for 120 days when compared to mice vaccinated for 21 days (Fig. S1C). Consistent with the enhanced IL-17 response there was also an enhanced granulocyte $\left(\mathrm{CD} 11 \mathrm{~b}^{+} \mathrm{GR} 1^{+}\right)$accumulation in the lungs of mice vaccinated 120 days before the Mtb infection (Fig. S1D). Together these data support the hypothesis that the nature of the T cells within the lung prior to Mtb challenge between the 21 day and 120 day vaccinated mice were quite different.

In order to determine if these different populations of antigenspecific $\mathrm{T}$ cells mounted a similar response to infection we compared the kinetics of antigen-specific cytokine responses following Mtb challenge. In unvaccinated mice, the Mtb infection resulted in the accumulation of Ag85-specific IFN- $\gamma$ and IL-17producing $\mathrm{T}$ cells peaking at day 21 post-infection, stabilizing thereafter (Fig. 2F). A similar profile was observed for IFN- $\gamma$ and IL-17 mRNA levels, although the initial increased transcription of genes encoding these cytokines was followed by a decrease after day 21 (Fig. 2G). As described above, there were higher numbers of both Ag85-specific-IFN- $\gamma$ - and IL-17-producing T cells in the lungs of vaccinated mice prior to Mtb infection (Fig. 2B, D and F). Upon Mtb challenge, the number of IFN- $\gamma$ and IL-17-producing antigenspecific $T$ cells did not change dramatically and were maintained at levels above completely naive mice throughout the infection (Fig. 2F). Thereafter, mice vaccinated for 120 days had lower numbers of Ag85-specific T cells (Fig. 2F). The same trend was observed for IFN- $\gamma$ and IL-17-producing ESAT-6-specific T cells (Fig. S1E).

These data demonstrate that the presence of both IFN- $\gamma$ - and IL-17-producing $\mathrm{T}$ cells in vaccinated mice at the time of challenge is associated with early growth arrest and long-lasting control of Mtb.

\subsection{Accumulation of a novel population of $C D 4^{+} I L-17^{+} T N F^{+} I L-2^{+}$ cells correlates with long-lasting control of Mtb}

While IFN- $\gamma$ is of critical importance in the control of Mtb $[12,13]$, the expression of this cytokine is not, by itself, a good correlate of protection [14-16]. We initially compared the frequency of IFN- $\gamma$ producing $\mathrm{CD} 4^{+} \mathrm{T}$ cells (grouped by dashed line in Fig. $3 \mathrm{~A}$ ) and found that mice vaccinated only 21 days prior to challenge had a higher frequency of these cells than the mice vaccinated 120 days prior to challenge (Fig. 3A). We then compared the frequency of $\mathrm{CD}^{+} \mathrm{T}$ cell co-expressing IFN- $\gamma$, TNF and IL-2, which have been associated with protection mediated by BCG [17-20]. We found
Based on the differences in protection afforded by BCG, shown
above, we asked whether these responses were associated with

CG-mediated control of Mtb correlates with the IL-17 response and is independent of the magnitude of the IFN- $\gamma$ response in the lung 

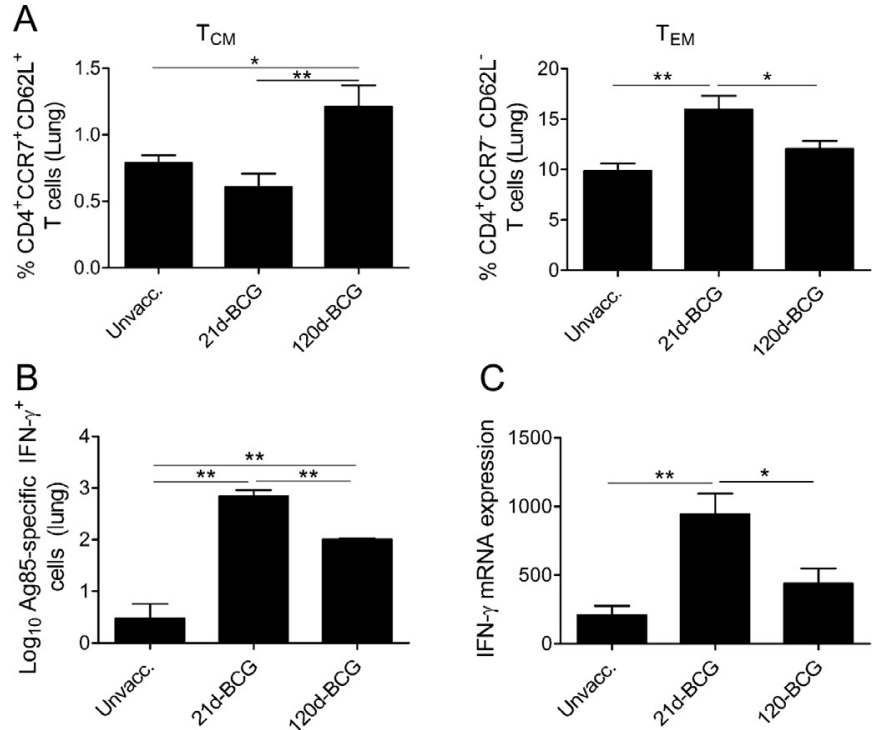

C
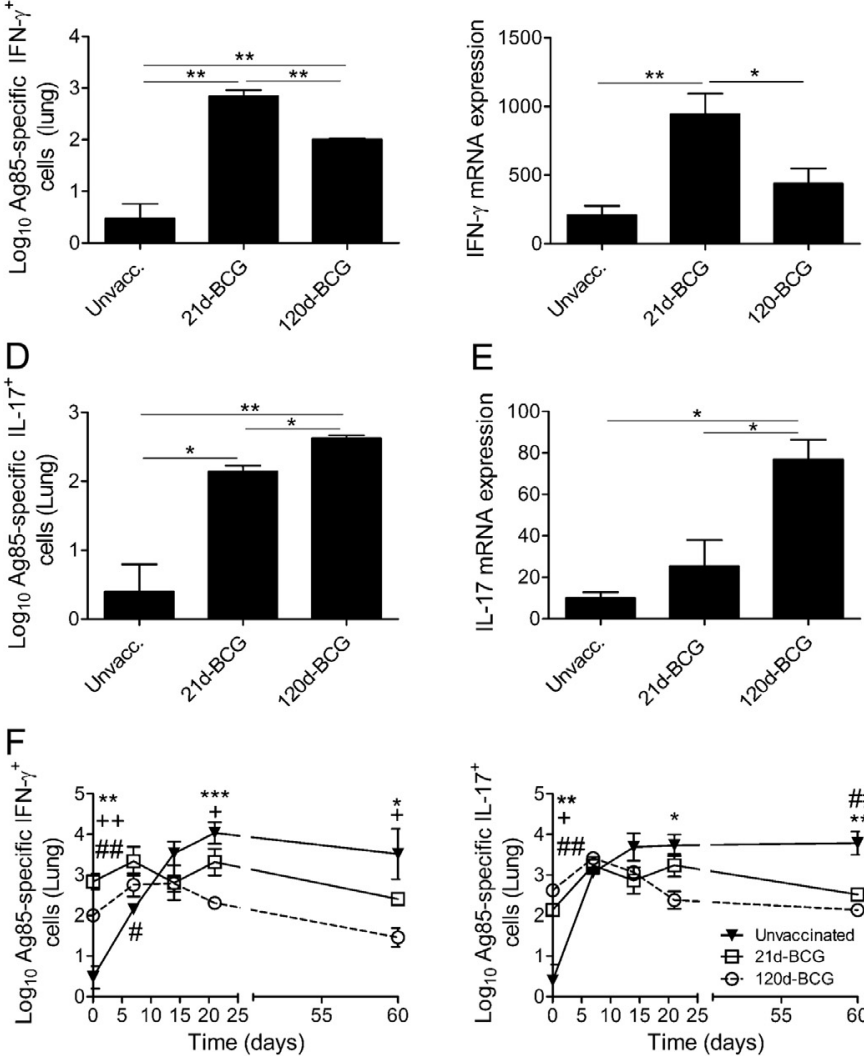

G
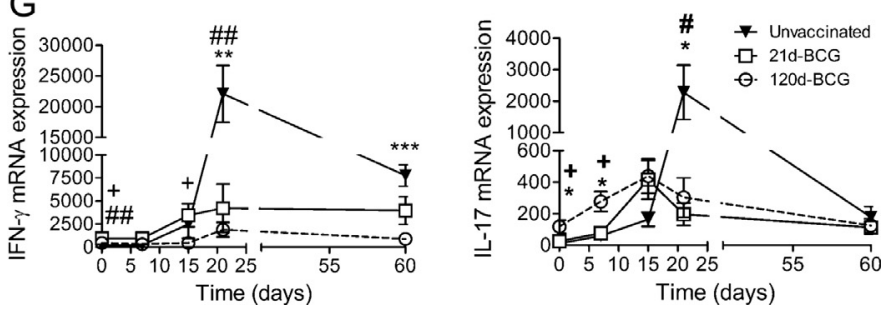

Fig. 2. The time between BCG vaccination and Mtb challenge impacts the phenotype and functionality of the $C D 4^{+} \mathrm{T}$ cell response. Mice were left unvaccinated (Unvacc.) or vaccinated with BCG for 21 days (21d-BCG) or 120 days (120d-BCG) prior to Mtb challenge. Cells were generated from the lungs, and the expression of CCR7 and CD62L was determined by flow cytometry in $\mathrm{CD}^{+} \mathrm{CD} 4^{+} \mathrm{T}$ cells (A) and the production of IFN- $\gamma$ (B) or IL-17 (D) was determined by ELISpot, after antigen stimulation. Messenger RNA was also isolated from the lungs of the same groups of mice and the level of expression of IFN- $\gamma(C)$ or IL-17 (E) determined by RT-PCR. $(n=6),{ }^{*} p<0.05 ;{ }^{* *} p<0.01 ;{ }^{* * *} p<0.001$ determined by two-way ANOVA. Unvaccinated (black triangles) and mice vaccinated for 21 days (white squares) or 120 days (white circles) were challenged with Mtb and the number of CD4T cells capable of producing IFN- $\gamma$ (F, left panel) or IL-17 (F, right panel) was determined by ELISpot. The expression of mRNA for IFN- $\gamma$ (G, left panel) and IL-17 (G, right panel) was also determined over time, post challenge $(n=6)$. ${ }^{*},+, \# p<0.05 ; ;^{* *},++, \# \# p<0.01 ;{ }^{* * *} p<0.001$, determined by two-way ANOVA; *, represents statistical differences between Mtb and 120d-BCG; \#, represents statistical differences between Mtb and 21d-BCG; +, represents statistical differences between 21d-BCG and 120d-BCG. Results are from one representative out of four independent experiments. that both groups of vaccinated mice had an increased percentage of lung IFN- $\gamma^{+} \mathrm{TNF}^{+} \mathrm{IL}-2^{+} \mathrm{CD} 4^{+} \mathrm{T}$ cells at the time of Mtb challenge, relative to unvaccinated mice (Fig. $3 \mathrm{~A}$ and $\mathrm{B}$ ) and that mice vaccinated 21 days before the Mtb challenge had the highest percentage of this population (Fig. $3 \mathrm{~A}$ and $\mathrm{B}$, blue bar and pie section). Moreover, the percentage of these cells remained high until day 12 post-infection, with mice vaccinated for 21 days consistently showing the highest frequency (Fig. 3B).

We next analyzed the characteristics of the $\mathrm{CD} 4^{+} \mathrm{IL}-17^{+} \mathrm{T}$ cells (represented by solid line in Fig. 3A). Since we did not detect $\mathrm{CD} 4^{+}$IFN- $\gamma^{+}$IL- $17^{+}$cells (not depicted), we focused on the IFN- $\gamma^{-}$ population. The IL-17 $7^{+}$population was strikingly higher in the 120 day vaccinated mice relative to the 21 day vaccinated and unvaccinated mice both prior to infection (Fig. $3 \mathrm{~A}$ ) and for the first 21 days post challenge (Fig. 3C). Among these $\mathrm{CD} 4^{+} \mathrm{IL}-17^{+}$cells, we found that the triple producing $\mathrm{IL}-17^{+} \mathrm{TNF}^{+} \mathrm{IL}-2^{+}$were the population that differed the most between both groups of vaccinated mice (Fig. 3A, shown by purple bar and purple pie slice and Fig. 3D). The differences in the lung populations were also observed in the draining lymph nodes (Fig. S2B-D).

Overall, these data suggest that a novel subset of multifunctional $\mathrm{CD} 4^{+} \mathrm{IL}-17^{+} \mathrm{TNF}^{+} \mathrm{IL}-2^{+} \mathrm{T}$ cells present at the time of challenge and during the early part of the response are associated with the ability of BCG-induced memory populations to provide long-lasting control of Mtb. The nature of the protective function of these cells will be dissected in the future namely by the determination of the role of IL17 itself or of any other molecule expressed by this subset of T cells.

\section{Discussion}

The Th1/Th2 paradigm proposed by Mosman and Coffman [31], followed by the identification of other Th cell phenotypes [32], brought new understanding of protective immune responses to infection. However, it is now well established that each $T$ cell phenotype incorporates a myriad of sub-populations that likely have different roles during infection [17,33-36]. Specifically for TB, the temporal correlation of Mtb growth arrest with the accumulation of $\mathrm{CD} 4^{+}$IFN $-\gamma^{+}$T cells suggests a critical role for this population in the control of the infection [8]. However, previous observations that IFN- $\gamma$ is not a good correlate of protection [14-16], achieving an early IFN- $\gamma$ response is not enough to control Mtb infection [37], and the data presented herein suggest that the $\mathrm{CD} 4^{+} \mathrm{T}$ cell populations that mediate immunity to TB are likely not IFN- $\gamma$-single producing Th1 cells, but subpopulations of this phenotype together with other cells whose effector function is not mediated by IFN- $\gamma$ [38,39].

The type of $\mathrm{T}$ cell that should be induced by vaccination to prevent Mtb infection and TB disease remains largely unknown [40,41]. Previous published data suggest that heterologous prime-boost strategies that potentiate IFN- $\gamma$ responses may not be enough [7]. Our data support this hypothesis and show that the effector and memory responses induced by BCG vaccination are functionally distinct, with the latter being more efficient at maintaining longlasting control of Mtb. Indeed, the effective long-term memory response is characterized mainly by $\mathrm{CD} 4^{+} \mathrm{IL}-17^{+}$multifunctional $\mathrm{T}$ cells, whereas the effector response is skewed to $\mathrm{CD} 4^{+} \mathrm{IFN}-\gamma^{+}$ multifunctional populations. These data are important as they provide a better understanding on the importance of different populations of $\mathrm{CD} 4^{+} \mathrm{T}$ cells in the control of primary Mtb infection and vaccine-mediated immunity. It has recently been suggested that one of the short comings of BCG is the poor induction of $\mathrm{CD} 4^{+}$ central memory populations [42] specifically, $\mathrm{CD}^{+} \mathrm{TNF}^{+} \mathrm{IL}-2^{+}$and $\mathrm{CD} 4^{+}$IFN- $\gamma^{+} \mathrm{TNF}^{+} \mathrm{IL}_{-} 2^{+}$multifunctional memory cells [17]. While our data support these observations, we were able to see distinct 
A
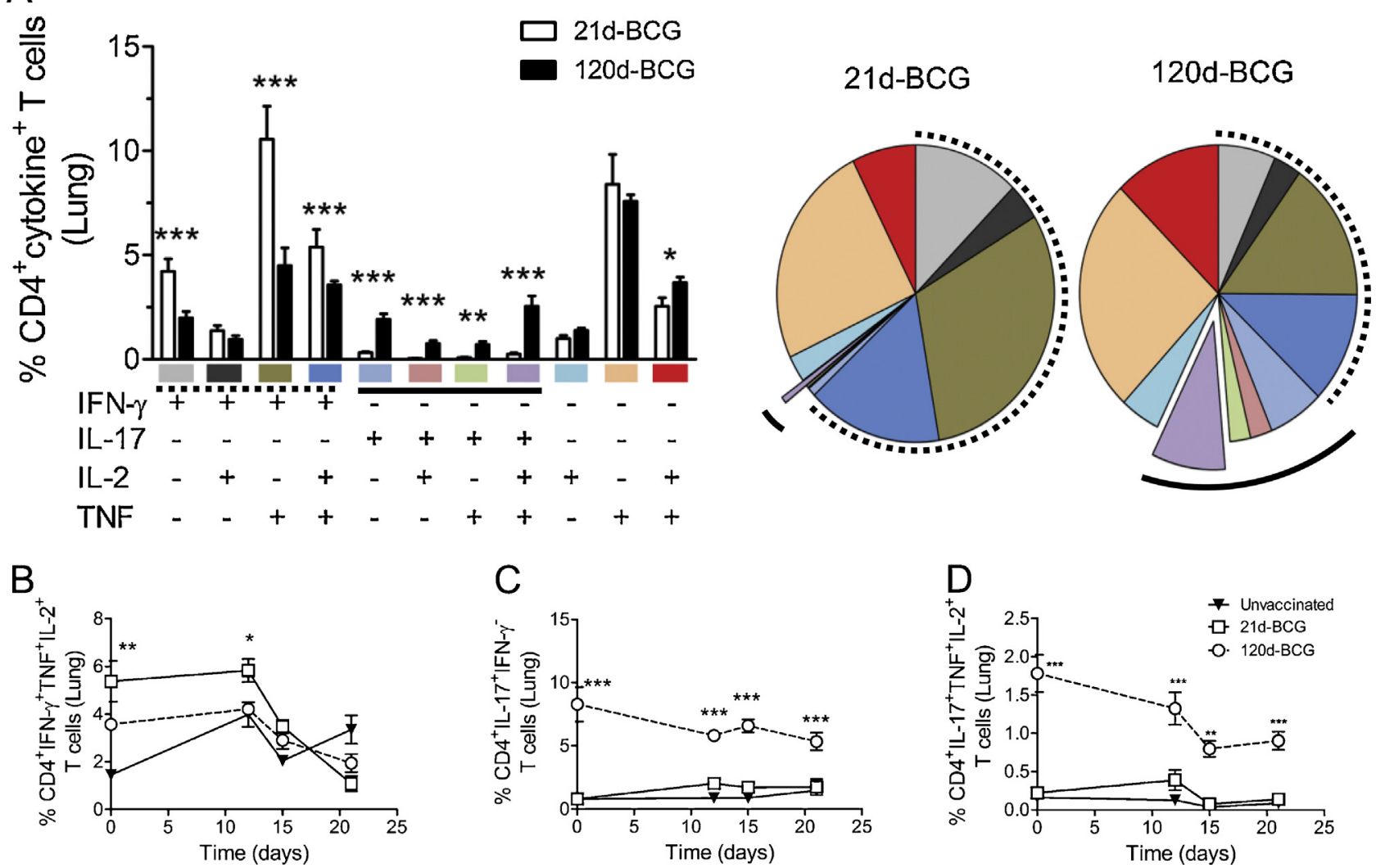

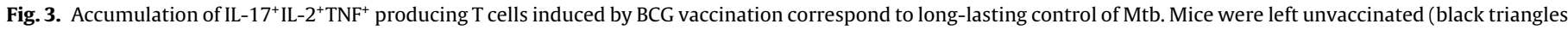

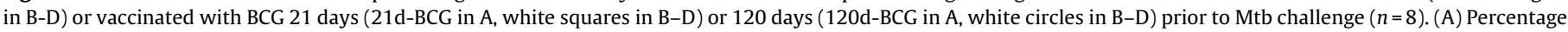

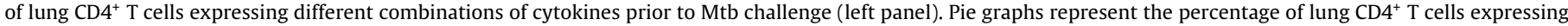

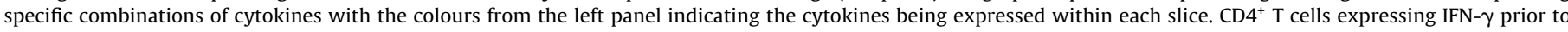

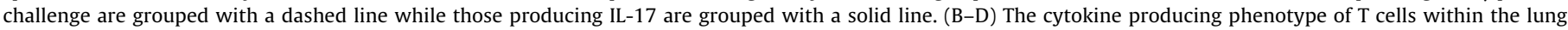

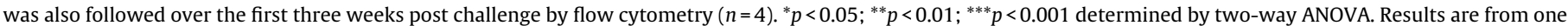
representative out of two independent experiments.

multifunctional $\mathrm{CD} 4^{+} \mathrm{IL}-17^{+}$populations after long-term $\mathrm{BCG}$ vaccination. We hypothesize that this population supplies the protective $\mathrm{CD}^{+} \mathrm{T}$ cell lung response as a result of becoming terminally differentiated [42]. The superior function of the IL-17 multifunctional memory populations is likely associated with their improved ability to survive and mediate effector function within the lung inflammatory environment. Indeed, it has been shown that human Th17 memory cells are relatively resistant to apoptosis and retain plasticity, converting into other Th cells [43]. Moreover, we have recently shown that different $\mathrm{CD} 4^{+} \mathrm{T}$ cell populations display a differential ability to survive and perform effector function in the infection site [10]. Future experiments are planned to address this issue. CD4 ${ }^{+} \mathrm{IL}-$ $17^{+}$cells have been recently shown to induce vaccine-mediated immunity in a CXCL13-dependent, IFN- $\gamma$-independent way, by promoting the recruitment and correct location of pro-inflammatory cytokine secreting CXCR5 cells within the lung tertiary lymphoid structures $[44,45]$. IL-17 is also an important inflammatory mediator for the recruitment of neutrophils during TB [21,46]. While the role of neutrophils during TB is still controversial, they can have protective roles including, but not limited to, the rapid clearing of Mtb released by dying macrophages in the granuloma [46,47]. Therefore, one can speculate that a vaccination approach that promotes a sustained, but controlled, recruitment of neutrophils in the context of an IFN- $\gamma$ rich environment within the lung is likely more advantageous than an approach that promotes the recruitment of macrophages alone, that serve as host cells for Mtb.
It is not only important that we define what comprises protective immunity but also how to maintain these responses with minimal pathological consequences to the host [48]. The data presented herein suggest that the protective memory response to TB must undergo a process of maturation capable of significantly reducing bacterial burdens without pathological consequences to the host. It is likely that the strain, dose, route and time postBCG vaccination as well as the genetic background of the host impact the generation and the kinetics of these populations. This would explain the differences observed in the generation of memory populations and protection afforded by BCG [42]. Moreover, while previous exposure to mycobacteria has been one of the factors associated with the variable protection afforded by BCG $[3,49]$, our data suggest that exposure to Mtb soon after vaccination may also contribute to the reduced efficacy of this vaccine. Likely this exposure further promotes the expansion of the effector response, hampering the development of the memory response.

Overall, our data show that the memory response generated by BCG vaccination can be very effective at mediating Mtb growth arrest and maintaining long-lasting control of bacterial burdens. Specifically, the accumulation of $\mathrm{CD} 4^{+} \mathrm{IL}-17^{+} \mathrm{TNF}^{+} \mathrm{IL}-2^{+} \mathrm{T}$ cells appears to be critical for these functions. This population is functionally distinct from the effector response and requires time to develop. It will be important in the future to determine whether the kinetics of this response is specific for BCG or a more general phenomenon induced by other live or subunit vaccines, currently in clinical trials. Understanding the mechanisms underlying the 
development and expansion of this population will have important implications for the development of novel vaccination strategies against TB and in heterologous prime-boost strategies wherein BCG is used as priming agent.

\section{Acknowledgements}

We thank the ICVS animal facility personnel for excellent animal husbandry. This work was supported by Fundação para a Ciência e Tecnologia, Portugal and cofunded by Programa Operacional Regional do Norte (ON.2-O Novo Norte), Quadro de Referência Estratégico Nacional (QREN), through the Fundo Europeu de Desenvolvimento Regional (FEDER) project grants PTDC/SAUMII/101977/2008, PTDC/BIA-BCM/102776/2008, and from Projeto Estratégico - LA 26 - 2013-2014 (PEst-C/SAU/LA0026/2013). AMC was funded by the National Institute of Allergy and Infectious Diseases at the National Institutes of Health grant AI46530. A.C. received a personal FCT grant SFRH/BPD/3306/2007 and M.S. is an FCT Investigator fellow.

\section{Appendix A. Supplementary data}

Supplementary data associated with this article can be found, in the online version, at http://dx.doi.org/10.1016/j.vaccine. 2014.11.013.

\section{References}

[1] WHO. Global tuberculosis control. WHO; 2011.

[2] Trunz BB, Fine P, Dye C. Effect of BCG vaccination on childhood tuberculous meningitis and miliary tuberculosis worldwide: a meta-analysis and assessment of cost-effectiveness. Lancet 2006;367:1173-80.

[3] Colditz GA, Brewer TF, Berkey CS, Wilson ME, Burdick E, Fineberg HV, et al. Efficacy of BCG vaccine in the prevention of tuberculosis. Meta-analysis of the published literature. JAMA 1994;271:698-702.

[4] Kaufmann SH. Future vaccination strategies against tuberculosis: thinking outside the box. Immunity 2010;33:567-77.

[5] Lambert PH, Hawkridge T, Hanekom WA. New vaccines against tuberculosis. Clin Chest Med 2009;30:811-26.

[6] Pitt JM, Blankley S, McShane H, O'Garra A. Vaccination against tuberculosis: how can we better BCG. Microb Pathog 2013;58:2-16.

[7] Tameris MD, Hatherill M, Landry BS, Scriba TJ, Snowden MA, Lockhart S, et al. Safety and efficacy of MVA85A, a new tuberculosis vaccine, in infants previously vaccinated with BCG: a randomised, placebo-controlled phase $2 \mathrm{~b}$ trial. Lancet 2013;381:1021-8.

[8] Cooper AM. Cell-mediated immune responses in tuberculosis. Annu Rev Immunol 2009;27:393-422.

[9] Khader SA, Bell GK, Pearl JE, Fountain JJ, Rangel-Moreno J, Cilley GE, et al. IL-23 and IL-17 in the establishment of protective pulmonary CD4 ${ }^{+} \mathrm{T}$ cell responses after vaccination and during Mycobacterium tuberculosis challenge. Nat Immunol 2007;8:369-77.

[10] Pearl JE, Torrado E, Tighe M, Fountain JJ, Solache A, Strutt T, et al. Nitric oxide inhibits the accumulation of $\mathrm{CD} 4^{+} \mathrm{CD} 44^{\text {hi }} \mathrm{Tbet}^{+} \mathrm{CD} 69^{\text {lo }} \mathrm{T}$ cells in mycobacterial infection. Eur J Immunol 2012;42:3267-79.

[11] Torrado E, Robinson RT, Cooper AM. Cellular response to mycobacteria: balancing protection and pathology. Trends Immunol 2011;32:66-72.

[12] Cooper AM, Dalton DK, Stewart TA, Griffin JP, Russell DG, Orme IM. Disseminated tuberculosis in interferon gamma gene-disrupted mice. J Exp Med 1993;178:2243-7.

[13] Green AM, Difazio R, Flynn JL. IFN-gamma from CD4 T cells is essential for host survival and enhances CD8 T cell function during Mycobacterium tuberculosis infection. J Immunol 2013;190:270-7.

[14] Goldsack L, Kirman JR. Half-truths and selective memory: Interferon gamma, CD4(+) T cells and protective memory against tuberculosis. Tuberculosis (Edinburgh) 2007;87:465-73.

[15] Tchilian EZ, Desel C, Forbes EK, Bandermann S, Sander CR, Hill AV, et al. Immunogenicity and protective efficacy of prime-boost regimens with recombinant (delta)ureC hly ${ }^{+}$Mycobacterium bovis BCG and modified vaccinia virus ankara expressing $M$. tuberculosis antigen 85A against murine tuberculosis. Infect Immun 2009;77:622-31.

[16] Leal IS, Smedegard B, Andersen P, Appelberg R. Failure to induce enhanced protection against tuberculosis by increasing T-cell-dependent interferon-gamma generation. Immunology 2001;104:157-61.

[17] Lindenstrom T, Agger EM, Korsholm KS, Darrah PA, Aagaard C, Seder RA, et al. Tuberculosis subunit vaccination provides long-term protective immunity characterized by multifunctional CD4 memory $\mathrm{T}$ cells. J Immunol 2009; 182:8047-55.
[18] Aagaard CS, Hoang TT, Vingsbo-Lundberg C, Dietrich J, Andersen P. Quality and vaccine efficacy of $\mathrm{CD} 4^{+} \mathrm{T}$ cell responses directed to dominant and subdominant epitopes in ESAT-6 from Mycobacterium tuberculosis. J Immunol 2009;183:2659-68.

[19] Scriba TJ, Tameris M, Mansoor N, Smit E, van der Merwe L, Isaacs F, et al. Modified vaccinia Ankara-expressing Ag85A, a novel tuberculosis vaccine, is safe in adolescents and children, and induces polyfunctional CD4+ T cells. Eur J Immunol 2010;40:279-90.

[20] Abel B, Tameris M, Mansoor N, Gelderbloem S, Hughes J, Abrahams D, et al. The novel tuberculosis vaccine, AERAS-402, induces robust and polyfunctional $\mathrm{CD}^{+}$and CD8 ${ }^{+} \mathrm{T}$ cells in adults. Am J Respir Crit Care Med 2010;181:1407-17.

[21] Torrado E, Cooper AM. IL-17 and Th17 cells in tuberculosis. Cytokine Growth Factor Rev 2010;21:455-62.

[22] Desel C, Dorhoi A, Bandermann S, Grode L, Eisele B, Kaufmann SH. Recombinant BCG DeltaureC hly ${ }^{+}$induces superior protection over parental BCG by stimulating a balanced combination of type 1 and type 17 cytokine responses. J Infect Dis 2011;204:1573-84.

[23] Orme IM. The kinetics of emergence and loss of mediator T lymphocytes acquired in response to infection with Mycobacterium tuberculosis. J Immunol 1987; $138: 293-8$

[24] Orme IM. Characteristics and specificity of acquired immunologic memory to Mycobacterium tuberculosis infection. J Immunol 1988;140: 3589-93.

[25] Cruz A, Fraga AG, Fountain JJ, Rangel-Moreno J, Torrado E, Saraiva M, et al Pathological role of interleukin 17 in mice subjected to repeated BCG vaccination after infection with Mycobacterium tuberculosis. J Exp Med 2010;207: 1609-16.

[26] Cruz A, Khader SA, Torrado E, Fraga A, Pearl JE, Pedrosa J, et al. Cutting edge: IFN-gamma regulates the induction and expansion of IL-17-producing CD4T cells during mycobacterial infection. J Immunol 2006;177:1416-20.

[27] Teixeira-Coelho M, Cruz A, Carmona J, Sousa C, Ramos-Pereira D, Saraiva AL, et al. TLR2 deficiency by compromising p19 (IL-23) expression limits Th17 cell responses to Mycobacterium tuberculosis. Int Immunol 2011;23: 89-96.

[28] Fraga AG, Cruz A, Martins TG, Torrado E, Saraiva M, Pereira DR, et al. Mycobacterium ulcerans triggers T-cell immunity followed by local and regional but not systemic immunosuppression. Infect Immun 2011;79:421-30.

[29] Sallusto F, Lenig D, Forster R, Lipp M, Lanzavecchia A. Two subsets of memory T lymphocytes with distinct homing potentials and effector functions. Nature 1999;401:708-12.

[30] Liu H, Rohowsky-Kochan C. Regulation of IL-17 in human CCR6 ${ }^{+}$effector memory T cells. J Immunol 2008;180:7948-57.

[31] Mosmann TR, Cherwinski H, Bond MW, Giedlin MA, Coffman RL. Two types of murine helper T cell clone I. Definition according to profiles of lymphokine activities and secreted proteins. J Immunol 1986;136:2348-57.

[32] Hirahara K, Poholek A, Vahedi G, Laurence A, Kanno Y, Milner JD, et al. Mechanisms underlying helper T-cell plasticity: implications for immune-mediated disease. J Allergy Clin Immunol 2013;131:1276-87.

[33] Beveridge NE, Price DA, Casazza JP, Pathan AA, Sander CR, Asher TE, et al. Immunisation with BCG and recombinant MVA85A induces long-lasting, polyfunctional Mycobacterium tuberculosis-specific CD4+ memory T lymphocyte populations. Eur J Immunol 2007;37:3089-100

[34] Darrah PA, Patel DT, De Luca PM, Lindsay RW, Davey DF, Flynn BJ, et al. Multifunctional TH1 cells define a correlate of vaccine-mediated protection against Leishmania major. Nat Med 2007;13:843-50.

[35] Kannanganat S, Ibegbu C, Chennareddi L, Robinson HL, Amara RR Multiple-cytokine-producing antiviral CD4T cells are functionally superior to single-cytokine-producing cells. J Virol 2007;81:8468-76.

[36] Wille-Reece U, Flynn BJ, Lore K, Koup RA, Miles AP, Saul A, et al. Toll-like receptor agonists influence the magnitude and quality of memory $T$ cell responses after prime-boost immunization in nonhuman primates. J Exp Med 2006;203:1249-58.

[37] Vilaplana C, Prats C, Marzo E, Barril C, Vegue M, Diaz J, et al. To achieve an earlier IFN-gamma response is not sufficient to control Mycobacterium tuberculosis infection in mice. PLoS One 2014;9:e100830.

[38] Gallegos AM, van Heijst JW, Samstein M, Su X, Pamer EG, Glickman MS. A gamma interferon independent mechanism of CD4T cell mediated control of M. tuberculosis infection in vivo. PLoS Pathog 2011;7:e1002052.

[39] Torrado E, Cooper AM. What do we really know about how CD4T cells contro Mycobacterium tuberculosis? PLoS Pathog 2011;7:e1002196.

[40] Kaufmann SH, McMichael AJ. Annulling a dangerous liaison: vaccination strategies against AIDS and tuberculosis. Nat Med 2005;11:S33-44.

[41] Walzl G, Ronacher K, Hanekom W, Scriba TJ, Zumla A. Immunological biomarkers of tuberculosis. Nat Rev Immunol 2011;11:343-54.

[42] Lindenstrom T, Knudsen NP, Agger EM, Andersen P. Control of chronic Mycobacterium tuberculosis infection by CD4 KLRG1- IL-2-secreting central memory cells. J Immunol 2013;190:6311-9.

[43] Kryczek I, Zhao E, Liu Y, Wang Y, Vatan L, Szeliga W, et al. Human TH17 cells are long-lived effector memory cells. Sci Transl Med 2011;3:104ra0.

[44] Gopal R, Rangel-Moreno J, Slight S, Lin Y, Nawar HF, Fallert Junecko $\mathrm{BA}$, et al. Interleukin-17-dependent CXCL13 mediates mucosal vaccineinduced immunity against tuberculosis. Mucosal Immunol 2013;6: 972-84.

[45] Slight SR, Rangel-Moreno J, Gopal R, Lin Y, Fallert Junecko BA, Mehra S, et al CXCR5(+) T helper cells mediate protective immunity against tuberculosis. J Clin Invest 2013;123:712-26. 
[46] Lowe DM, Redford PS, Wilkinson RJ, O'Garra A, Martineau AR. Neutrophils in tuberculosis: friend or foe. Trends Immunol 2012;33:14-25.

[47] Yang CT, Cambier CJ, Davis JM, Hall CJ, Crosier PS, Ramakrishnan L. Neutrophils exert protection in the early tuberculous granuloma by oxidative killing of mycobacteria phagocytosed from infected macrophages. Cell Host Microbe 2012;12:301-12.
[48] Sterne JA, Rodrigues LC, Guedes IN. Does the efficacy of BCG decline with time since vaccination. Int J Tuberc Lung Dis 1998;2:200-7.

[49] Fine PE. Variation in protection by BCG: implications of and for heterologous immunity. Lancet 1995;346:1339-45. 